\title{
O "eu posso" deve poder acompanhar todas as minhas determinações: a noção de existência e a doutrina transcendental das modalidades
}

\section{The "I can" must be capable of accompanying all my determinations: the notion of existence and the transcendental doctrine of modalities}

Prof. Dr. Róbson Ramos dos Reis robsonramosdosreis@gmail.com Universidade Federal de Santa Maria, Brasil

O tema deste artigo é a noção de possibilidade na fenomenologia hermenêutica de Martin Heidegger. O tópico é examinado no contexto da interpretação feita por Heidegger da doutrina kantiana das modalidades na Crítica da Razão Pura. O meu objetivo consiste em mostrar que essa interpretação representa uma ampliação e radicalização da análise transcendental das modalidades, na medida em que a finitude implicada pela noção existencial de possibilidade sugere a suspensão do Princípio de Plenitude no domínio existencial. Uma consequência sugerida ao final do artigo é que, assim como na abordagem transcendental da filosofia crítica, a ampliação para além do significado puramente lógico das modalidades também exibe um significado crítico do tratamento fenomenológico.
\end{abstract}

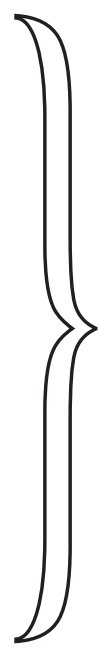

\section{PALAVRAS-Chave Heidegger; Kant; Modalidades; Possibilidade; \\ Princípio de Plenitude}

The topic of this paper is the notion of possibility in Martin Heidegger's hermeneutic phenomenology. The context of analysis is the interpretation given by Heidegger to the Kantian doctrine of modalities, such as presented in the Critique of Pure Reason. My aim is to show that this interpretation entails an extension and radicalization of the transcendental analysis of modalities, to the extent that the finitude implied by the notion of existential possibility suggests the suspension of the Principle of Plenitude in the existential domain. As a conclusion, I will propose that the analytical movement made in the phenomenological account beyond a purely logical treatment of the modalities has a critical meaning just like the transcendental approach in the critical philosophy.

KEYWORDS Heidegger. Kant. Modalities. Possibility. Principle of Plenitude.

*Este trabalho recebeu o apoio do CNPq, tendo sido apresentado no IV Congresso Luso-brasileiro de Fenomenologia, Rio de Janeiro, 2013. Agradeço os comentários e observações críticas apresentados pelos colegas presentes. 
Uma das características mais controversas da proposta meta-ontológica da fenomenologia hermenêutica de Heidegger consiste na exigência de que é preciso reconhecer diferentes modos de ser irredutíveis (MCDANIEL, 2009, p. 290; CARMAN, 2013, pp. 89-91). Além disso, a diferença nas maneiras de formação de individuação, determinação e fenomenalização qualifica-se ainda mais, porque também é estabelecida a pretensão de que haveria um modo particular, o modo de ser do ser-aí, caracterizado por possibilidades numa acepção especial do termo. Em consonância, a maneira de determinação nos entes que têm o modo de ser do ser-aí não acontece a partir de propriedades, mas sim por possibilidades. Como é sabido, a noção de possibilidade existencial não designa a possibilidade lógica, por exemplo, o pensável sem contradição. De outro lado, a noção também não é entendida como a contingência, ou como o possível disjuntivo, que seriam especificações semânticas da possibilidade como categoria modal da subsistência.

Também já foi amplamente estudada a interpretação ontológica feita por Heidegger dos Princípios do Entendimento Puro, na Crítica da Razão Pura. Como é sabido, Heidegger interpreta os três primeiros grupos de princípios como a expressão de uma ontologia da subsistência, entendida no sentido restrito da projeção da natureza requerida para uma ciência físico-matemática do natural. De modo consistente com o reconhecimento explicitamente feito por Kant da diferença entre os princípios modais em relação aos três primeiros grupos de princípios, Heidegger apresenta uma interpretação dos Postulados do Pensamento Empírico em Geral como possuindo um significado muito especial, dado que não seriam expressões de determinações reais dos objetos. Por conseguinte, o significado ontológico desses princípios é muito peculiar, pois não apresentam determinações formais de objetos. Por outro lado, nos Postulados há uma exposição do significado das noções modais que não se limita a uma consideração lógica.

Com base nestas duas referências interpretativas, abordarei no presente trabalho um tema relacionado com a interpretação heideggeriana dos princípios modais do entendimento puro. Neste sentido, o problema geral que abordarei consiste em saber se existem elementos da abordagem transcendental das modalidades na elaboração do modelo meta-ontológico de Heidegger. A interrogação não é artificial, porque a ampliação do tratamento das modalidades para além de uma abordagem lógica aproxima o modelo meta-ontológico da abordagem transcendental kantiana. Contudo, a admissão de um modo de ser determinado por possibilidades introduz uma diferença substantiva. A semelhança e a diferença nas duas perspectivas filosóficas justificam, portanto, um exame 
mais detalhado do possível vínculo entre a noção existencial de possibilidade e a abordagem transcendental das modalidades na doutrina crítica dos princípios modais, na Crítica da Razão Pura.

A resposta afirmativa ao problema é plausível, a despeito da objeção de que na abordagem transcendental das noções modais haveria apenas uma elucidação da possibilidade como categoria modal da subsistência. Não obstante, pode-se entender que a interpretação fenomenológica das modalidades consiste em uma ampliação e radicalização da perspectiva transcendental. Num nível mais básico é essa a relação que o próprio Heidegger reconhece, quando, ao final da sua interpretação da dedução transcendental, afirma o seguinte:

Caso se radicalize o problema kantiano do conhecimento ontológico, no sentido de não limitá-lo apenas à fundação positiva das ciências positivas e de, além disso, não entendê-lo como problema do juízo, mas se o entenda como a pergunta radical e fundamental pela possibilidade do compreender de ser, então resulta a problemática filosófica fundamental de "Ser e Tempo" (HEIDEGGER, 1987, p. 426).

A ampliação mencionada por Heidegger designa a consideração das condições ontológicas requeridas não apenas para a tematização científica, mas para toda forma de relação intencional com entes. Mais ainda, a ampliação para além do problema do juízo significa uma abertura para além das condições da referência descritiva aos entes, e também contém a sugestão de que em seus estratos mais básicos a estrutura da intencionalidade não seria conceitualmente mediada. O tema é conhecido na fenomenologia. Para Heidegger, porém, o mais importante é o reconhecimento de que em todos os contextos intencionais, e não apenas nos judicativos e das práticas epistêmicas, está pressuposto na estrutura do comportamento intencional uma compreensão do modo de ser dos entes que ocupam a posição de intentum da intencionalidade. No que se segue, examinarei três tópicos em que se pode verificar a ampliação mencionada por Heidegger. $\mathrm{O}$ foco da minha atenção estará concentrado no domínio mais específico das noções modais, em particular do conceito de possibilidade, de acordo com a interpretação feita por Heidegger dos Postulados do Pensamento Empírico em Geral. 
O "eu posso" deve poder acompanhar todas as minhas determinações: a noção de existência e a doutrina transcendental das modalidades
Prof. Dr. Róbson Ramos dos Reis

[Universidade Federal de Santa Maria - Brasil]

O primeiro tópico relaciona-se com o estatuto sintético dos Postulados. Os princípios modais são sintéticos não objetivamente, mas subjetivamente (KANT, 1980, A 234/B 286). Heidegger infere desta característica a dependência dos princípios modais em relação aos demais princípios categoriais, desde onde as noções modais ganham a sua determinação (HEIDEGGER, 1987, p. $187)^{1}$. Segundo Kant, o conceito de possibilidade é elucidado em termos da conformidade com as condições formais da experiência. Sendo mais exato, o significado do conceito de possibilidade é relativo à noção formal de objeto como algo dotado de quantidades extensivas e intensivas, que, além disso, está subordinado aos princípios de permanência, causação e interação (GUYER, 1998, p. 299). Portanto, sob a condição de que não se deva permanecer apenas com a elucidação lógica das noções modais, esta relatividade significa em termos gerais que o espaço modal é dependente de um compromisso ontológico particular, do qual se seguem critérios de existência e condições da satisfação destes critérios.

Esta exigência está preservada e ampliada no modelo meta-ontológico proposto por Heidegger. A simples qualificação da noção ontológica usual de possibilidade como uma "categoria modal da subsistência" já indica isso, na medida em que a admissão de outros modos de ser além da subsistência, como disponibilidade, vida, consistência e o modo de ser da existência (no sentido técnico cunhado por Heidegger), amplia o espaço do campo modal. Deste modo, é admissível falar de categorias modais da disponibilidade, categorias modais da vida, categorias modais da existência, etc. Naturalmente, em todos estes casos estaria preservada a exigência de determinação interna das noções modais. Considerando que a análise meta-ontológica não assume um procedimento redutivo, no sentido de examinar relações de derivação ou dependência forte entre os modos de ser, então essa mesma autonomia estaria presente no espaço modal, o que explicaria a ausência de um tratamento ramificado e genealógico das modalidades na fenomenologia hermenêutica. ${ }^{2}$

1 Nos estudos filológicos afirmou-se criticamente que as elucidações que vinculam a doutrina kantiana das modalidades com o problema da subjetividade, da posição subjetiva e da unidade sintética da apercepção seriam por vezes extravagantes. Naturalmente, a interpretação de Heidegger figura entre os casos identificados (MOTTA, 2012, pp. 18-20). Não é o meu objetivo neste trabalho discutir criticamente tal objeção, mas sustento que uma leitura mais detalhada dessa interpretação perceberia que não há uma dissociação entre uma teoria da objetividade e a síntese subjetiva, o que talvez seja exatamente uma das diferenças entre a filosofia crítica e a ontologia da metafísica das escolas.

2Esta objeção foi apresentada em contraste com o tratamento sistemático mais desenvolvido e completo - ramificado e genético -, que estaria presente na fenomenologia husserliana (MOHANTY, 1999, p. 164). 
No entanto, a complexidade do campo modal, introduzida com a admissão de diferentes modos de ser irredutíveis, é ampliada ainda mais, dado que Heidegger sustenta que há um modo de ser que se diferencia dos demais em razão da sua maneira específica de determinação. Os entes que possuem o modo de ser do ser-aí não recebem a sua determinação caractérica a partir de propriedades, mas sim de possibilidades: as possibilidades existenciais. Em outros termos, entes que possuem o modo de ser do ser-aí não se determinam por propriedades, mas por maneiras e possibilidades, o que implica o tipo especial de formação de identidade que acontece nesse modo de ser. Entra em jogo neste contexto uma noção distinta de possibilidade, relacionada com o que se costuma chamar de possibilidades dinâmicas (VON WRIGHT, 1951, p. 28) e que pertenceria ao plano da determinação ontológica propriamente dita. Neste caso, a dificuldade reside em elucidar o campo modal correspondente a uma ontologia em que as determinações primitivas não se dão por propriedades, mas por maneiras que são possibilidades dinâmicas (propriedades de habilidade). Há um fator complicador adicional em relação a este ponto, dado que Heidegger emprega a noção de possibilidade existencial em um segundo sentido nominal, que também conduz a uma nova ampliação no modelo meta-ontológico. Para examinar este tópico, é relevante considerar outro aspecto da intepretação heideggeriana do estatuto sintético dos juízos modais, a saber, que não apenas os Postulados são sintéticos, mas as próprias categorias modais, quando empregadas em juízos sobre objetos específicos, possuem uma natureza sintética.

\section{- 3 -}

Heidegger entende a característica sintética de enunciados em que as noções modais figuram como predicados no sentido de que tais enunciados expressam uma posição em relação ao sujeito cognoscente e suas capacidades cognitivas, mais exatamente, uma posição em relação às condições da experiência de objetos. A análise das modalidades significa, por conseguinte, um desdobramento da doutrina do ser como posição, mais especificamente da posição absoluta (HEIDEGGER, 1996a, pp. 467-469). Num ponto especialmente técnico, Heidegger ressalta que estas condições formais localizadas nas próprias faculdades de representação demandam uma condição básica, relacionada com ação sintética do agente cognoscente (HEIDEGGER, 1987, p. 187). Em última instância, a unidade sintética da apercepção é requerida, em conjunto com a esquematização das regras categoriais, para que seja possível experiência de objetos e, portanto, objetos da experiência (HEIDEGGER, 1996a, p. 469). 
O "eu posso" deve poder acompanhar todas as minhas determinações: a noção de existência e a doutrina transcendental das modalidades
Prof. Dr. Róbson Ramos dos Reis [Universidade Federal de Santa Maria - Brasil]

O problema que se coloca aqui refere-se, por conseguinte, à presença ou mesmo à necessidade de um análogo da doutrina da apercepção transcendental no modelo meta-ontológico ampliado. Responder a esta questão demanda uma reconstrução de dois elementos importantes da interpretação heideggeriana da filosofia transcendental de Kant: a própria doutrina da apercepção transcendental e, num nível mais geral, a doutrina kantiana da personalidade, que inclui a consideração da personalidade moral além das personalidades empírica e transcendental. ${ }^{3}$ Certamente não é o caso de fazer isso agora. Não obstante, sim é importante registrar um aspecto da noção existencial de possibilidade que está em conexão com o problema da apercepção.

A questão é que todos os modos de ser admitidos no modelo meta-ontológico estão referidos, como condições da intencionalidade, a um modo de ser particular, que deve ser caracterizado como possibilidade. Em outros termos, as possibilidades existenciais são as determinações caractéricas de entes qualificados como um poder-ser. Não fora o ser-aí um poder-ser, não haveria abertura significativa na qual acontecem os comportamentos intencionais. Sobre isso, considere-se as seguintes declarações que Heidegger fez a propósito do eu-penso da apercepção transcendental.

No campo da subjetividade, onde a liberdade determina primariamente o modo de ser do sujeito e esse modo de ser é caracterizado pelo eu-posso, o ser capaz (das Vermögen), quer dizer, a possibilidade, é o mais alto em relação à efetividade. Aqui a efetividade não constitui a existência, mas o eu-posso como eu-sou-capaz... portanto, exatamente em sua efetividade o eu é pura possibilidade, o eu-posso é exatamente a existência existente (existente Existenz, HEIDEGGER, 1987, pp. 379 e 380).

Mesmo sem analisar esta decisiva passagem ${ }^{4}$, vê-se como a tese da prioridade do possível sobre a efetividade no campo existencial é relacionada por

$3 \mathrm{~A}$ interpretação fenomenológica da doutrina transcendental da personalidade foi apresentada nos Problemas Fundamentais da Fenomenologia (HEIDEGGER, 1976, §§ 14-15). A recente publicação dos seminários sobre Kant dá testemunho da intensidade da ocupação de Heidegger com a filosofia prática de Kant no início dos anos trinta (HEIDEGGER, 2013).

4Antônio Aguirre indicou uma importante conexão conceitual entre a tese da prioridade do possível em Ser e Tempo e alguns elementos da noção husserliana de possibilidade prática (AGUIRRE, 1991, pp. 152-153). 
Heidegger com a doutrina da apercepção transcendental. Deste modo, um dos significados do conceito existencial de possibilidade não designa tão somente outro campo regional ontológico, mas, ao ser relacionado como requerimento para compreender a apercepção transcendental, situa-se no plano ontológico fundamental estrito senso. Portanto, a conhecida tese heideggeriana sobre o primado do possível - a possibilidade está acima da efetividade - possui uma relevância não apenas regional, mas que alcança as condições gerais de todo encontro intencional significativo. Isto leva ao terceiro ponto de conexão da concepção existencial de possibilidade com da doutrina kantiana dos princípios sintéticos do entendimento.

O tópico em questão agora diz respeito ao princípio supremo dos juízos sintéticos, a saber, que "as condições de possibilidade da experiência em geral são, ao mesmo tempo, as condições de possibilidade dos objetos da experiência [...]" (KANT, 1980, A 158/B 197). Heidegger interpreta esse princípio como sendo um caso de um conhecimento fenomenológico originário, cujo conteúdo está expresso particularmente em cada princípio particular. Deste modo, o princípio supremo dos juízos sintéticos é a expressão da estrutura ekstático e horizontal da transcendência, que forma um horizonte desde onde é possível ao objeto estar situado como objeto (HEIDEGGER, 1991, p. 119). A formação de horizontes de manifestação de algo como algo determinado é possibilitada na própria transcendência. Vê-se aqui um sentido verbal do termo possibilidade que, em conjunto com as duas acepções nominais (possibilidades dinâmicas e o poder-ser), compõe o fenômeno da possibilidade como categoria modal da existência humana. De acordo com o significado verbal, o existir humano, que é originariamente um poder-ser, projeta-se em possibilidades dinâmicas, formando assim uma identidade singular determinada. Esse projetar-se também tem um significado modal, o uso verbal de "possibilitar", "ser capaz de", entendido como o possibilitar a identificação própria a partir das possibilidades dinâmicas.

Contudo, não se forma apenas uma ipseidade individuada por possibilidades, mas também os horizontes de manifestação fenomenológica de entes e objetos. Projetando-se em possibilidades dinâmicas os seres humanos possibilitam e formam os horizontes que contém os critérios de identidade e existência para os entes que vêm ao encontro desde tais horizontes. Pode-se dizer, por 
conseguinte, que a transitividade da possibilidade em sentido verbal tem como agente o ser humano como um poder-ser, mas que se dirige ou finaliza não apenas em habilidades dinâmicas auto-identificadoras, mas nos diferentes modos ou sentidos de ser que estruturam a horizonticidade dos comportamentos intencionais. Uma conhecida passagem de Ser e Tempo põe em evidência o tópico:

O disponível como tal está descoberto em sua utilizabilidade, empregabilidade, e nocividade. A totalidade de conformidade desvela-se como o todo categorial de uma possibilidade da conexão de disponível. Mas também a "unidade" dos múltiplos entes subsistentes, a natureza, somente se torna capaz de descoberta (entdeckbar) sobre a base da abertura de uma possibilidade sua. É um acaso que a pergunta pelo ser da natureza vise às "condições de sua possibilidade"? Sobre o que se funda tal perguntar? Diante dele não se pode deixar de fora a pergunta: por que o ente que não é conforme ao ser-aí (nichtdaseinsmässiges Seiendes) é compreendido em seu ser quando é aberto a partir das condições de sua possibilidade? (HEIDEGGER, 1986, pp. 144-145).

A posição é formulada em termos de perguntas, mas em última instância é sugerido que o campo da possibilidade existencial não designa apenas um âmbito modal específico, distinto da possibilidade em sentido lógico e também da possibilidade como categoria modal da subsistência, mas ele representa o campo modal enquanto tal. Naturalmente, este tópico crucial precisa ser elucidado em detalhe, mas não é o caso de fazê-lo agora.

O meu objetivo, antes disso, era o de indicar de que modo, mesmo que com profundas mutações, certa herança transcendental deixa-se reconhecer no modelo meta-ontológico proposto na fenomenologia hermenêutica, no centro do qual estão a noção de modo de ser e a estrutura da possibilidade existencial. As mutações evidentes diriam respeito, de um lado, à ampliação do espaço lógico dos comprometimentos ontológicos, com a admissão de diferentes modos irredutíveis de ser além daquele expresso nos Axiomas, Antecipações e Analogias. De outro lado, a estruturação modal da existência humana, no sentido de que a própria transcendência possui integralmente uma estrutura modal, também exibe uma ampliação em relação à abordagem transcendental, na medida em que a possibilidade não é apenas a posição de condições de existência segundo 
um determinado compromisso ontológico, mas a formação de horizontes ontológicos que são eles mesmos compreendidos como possibilidades. Por fim, a ampliação é visível ao se considerar que a formação de horizontes modais tem um sentido temporal peculiar, desde onde configura-se uma historicidade nos campos modais da existência e da formação de sentidos de ser.

Este é um tema que posso apenas sugerir no presente contexto, sem oferecer uma análise filologicamente documentada. A tese é que a historicidade dos entes que são ser-aí, ao transladarem-se para os contextos intencionais formados pelas possibilidades existenciais, introduziria uma historicidade nos próprios modos de ser. Com base na hipótese de uma historicidade dos sentidos de ser, seria admissível, então, o modelo de uma história das possibilidades internas - outra denominação para os modos de ser-, cuja finitude limitaria sem interditar o projeto de uma interpretação dos diferentes sentidos do possível em cada modo de ser.

Contudo, neste ponto já se insinua a suspeita de que a radicalização mencionada pelo próprio Heidegger ao descrever a relação entre a temática de Ser e Tempo e a filosofia transcendental não seria apenas uma ampliação, mas também uma subversão heterodoxa. Com este tema encerrarei o presente trabalho, no intuito de apenas exibir a hipótese de que o campo modal da existência, ao diferenciar-se da estruturação modal da subsistência, contém uma restrição daquela legalidade modal que foi expressa de forma não interpretada no Axioma II do sistema modal de Becker, cuja intepretação seria a frequência estatística (BECKER, 1952, pp. 10, 16-19) e, talvez, o princípio de plenitude (LOVEJOY, 1936, p. 52, KNUUTTILA, 1981, p. vii).

\section{$-5-$}

Nas considerações precedentes tentei estabelecer a hipótese de que o modelo meta-ontológico proposto por Heidegger preserva e amplia aspectos da abordagem transcendental das modalidades. Em termos resumidos, esse modelo propõe a admissão de uma diversidade de modos de ser irredutíveis, que são normativos em relação às formas de determinação e individuação, e entre os quais o modo de ser da existência humana precisa ser compreendido de maneira muito especial, pois a possibilidade seria a determinação ontológica mais elevada neste modo de ser. De acordo com Heidegger, o caráter sintético dos 
princípios modais significa a relatividade das estruturas modais a um compromisso ontológico específico, e no modelo ampliado essa dependência implica a admissão de uma diversidade de campos modais correspondentes aos diferentes sentidos de ser. Além disso, o estatuto sintético das próprias modalidades significa a posição da conformidade com as condições da experiência, o que conduz, em última instância, ao princípio da unidade da apercepção transcendental. No campo existencial, este não seria o ponto final na apresentação das condições gerais do encontro significativo com entes e objetos, o qual deveria ser reconhecido num sentido de possibilidade como poder-ser, de modo que seria necessário dizer que o "eu posso" tem de acompanhar todas as minhas determinações. Por fim, a relação com o princípio supremo dos juízos sintéticos estaria preservada e ampliada no contexto da possibilidade existencial, que possuiria também uma acepção ativa ou verbal, designando o acontecimento da formação de um horizonte que possibilita o encontro significativo com entes. Assim sendo, os diferentes modos de ser precisariam ser vistos como formados pelo poder-ser projetivo da existência humana. Por certo, na doutrina da temporalidade é que estaria o núcleo abstrato mais específico da ampliação.

Esta hipótese admite, portanto, um movimento de ampliação da filosofia transcendental na fenomenologia hermenêutica. Se assim for, então o espaço da existência representaria o campo modal como tal e a autonomia dos diferentes sentidos de ser não seria incompatível com uma elucidação ramificada dos respectivos campos modais a partir da temporalidade das possibilidades existenciais. No que se segue, pretendo sugerir brevemente que a ampliação precisa ser qualifica a partir da ideia de radicalização proposta pelo próprio Heidegger, gerando uma extensão não conservadora em um aspecto muito fundamental.

Um dos problemas suscitados pela doutrina transcendental das modalidades referia-se à questão de se, mesmo com o seu sentido crítico, essa doutrina estaria comprometida como uma ontologia da subsistência. A despeito da sedução de uma resposta trivial, há uma linha argumentativa estritamente modal, que consiste em determinar o compromisso com uma ontologia da subsistência a partir de dois elementos: 1) uma análise da dependência intermodal nos termos de implicação estrita (o Axioma II no sistema modal de Oskar Becker), 2) a interpretação deste axioma como frequência estatística, seguindo-se daí a admissão do Princípio de Plenitude. Se a doutrina crítica estiver comprometida com tais elementos, então ela seria relativa à ontologia da subsistência. Contudo, aparentemente não seria necessário concluir que, mesmo sendo o Princípio 
de Plenitude implicado na abordagem transcendental ${ }^{5}$, que o Princípio por si mesmo implicasse uma ontologia da subsistência. O problema novo é saber se a estruturas modais da existência implicam um afastamento do Princípio de Plenitude, ou seja, dado o compromisso da elucidação transcendental das modalidades com o referido princípio, este é o ponto preciso em que a abordagem fenomenológico-hermenêutica da noção de possibilidade não representaria apenas uma ampliação, mas implicaria uma radicalização heterodoxa.

Não justificarei a minha resposta a este problema agora, mas apenas firmarei a posição que deve ser provada em outra ocasião. A minha convicção é que no domínio existencial não vale o Princípio de Plenitude ${ }^{6}$. A base desta posição é o traço específico da noção existencial de possibilidade, que é caracterizada por uma negatividade, entendida como a não efetivação. Possibilidades existenciais preservam a sua existencialidade na projeção e, como tais, não se efetivam, sempre trazendo conjuntamente consigo outras possibilidades dinâmicas, e sempre excluindo um novo grupo de possibilidades na projeção acontecida. Pode-se dizer que tese da primazia do possível sobre o efetivo é a expressão desta inversão nas relações intermodais no plano existencial. Deste modo, as possibilidades dinâmicas nunca se efetivam como estados, o poder-ser existencial não é uma determinação segundo uma categoria, e a formação de horizontes de compreensão sempre é a retração ou não formação de outras possibilidades horizontais, isto é, para que os horizontes tenham normatividade é preciso que aconteça uma modalização que modifique os sentidos de ser, modificação que tem o sentido de uma retração ou não efetivação de possibilidades ${ }^{7}$.

Caso isso possa ser sustentado, a consequência menos forte é a restrição da validade do Princípio de Plenitude, que vigoraria apenas no campo modal da ontologia da subsistência. Uma posição intermediária sustenta que para cada modo de ser haveria um análogo específico do Princípio, e ainda seria necessário examinar se, mesmo com um sentido próprio, haveria um compromisso

5 Conclusão que não resulta de uma análise simples, tal como mostraram Hintikka e Kannisto (HINTIKKA, et al., 1981).

6 Sem uma reconstrução do significado das demais noções modais no campo da existência não há uma base suficiente para inferir qual seria o compromisso no modo de ser do ser-aí com a implicação intermodal exposta no Axioma II.

7 Esta é uma tese interpretativa forte que precisa ser documentada, pois sustenta que a força vinculante das possibilidades existenciais e dos respectivos horizontes nos contextos intencionais seria dependente da não efetivação existencial de possibilidades. Sem entrar propriamente na análise, indico pelo menos duas fontes relevantes: HEIDEGGER, 1983, p. 528; HEIDEGGER, 1996a, p. 167. Figal (2001, pp. 204-205) apresentou esta característica da noção de possibilidade existencial no contexto de uma interpretação do conhecido tema do último deus e da fuga dos deuses na obra de Heidegger. 
no modo de ser do ser-aí com uma tese de que todas genuínas possibilidades existenciais alguma vez encontram efetivação existencial. Uma consequência mais forte seria a completa revogação do Princípio, dado que também o modo de ser da subsistência, entendido como um horizonte formado desde a retração de outros horizontes, estaria subordinado a um campo modal mais básico em que tal princípio não teria vigor. Uma decorrência desta conclusão não seria apenas a impossibilidade de oferecer qualquer prova transcendental dos horizontes ontológicos, mas também a admissão de uma historicidade na formação das possibilidades existenciais, na identidade existencial (não apenas individual) e na própria formação dos sentidos de ser. Considerando a intrínseca retração de possibilidades e horizontes de abertura significativa, então essa negatividade não poderia ser superada de algum modo, por exemplo, em uma teleologia histórica. O campo modal, sempre relativo a determinados modos de ser e compromissos ontológicos, seria dotado de uma opacidade não eliminável. Contudo, essa é uma consequência assumida apenas de modo condicional, pois seria necessário examinar em detalhe se a finitude e a historicidade das possibilidades existenciais implicariam de fato um descompromisso com o Princípio de Plenitude.

Considerando a reconstrução esboçada até aqui, a questão decisiva parece-me ser, num nível muito geral, o problema da identificação das razões que justificam a ampliação e radicalização no tratamento fenomenológico e hermenêutico das modalidades. $\mathrm{O}$ contexto de resposta está indicado no sentido crítico que reside na ampliação de um conceito simplesmente lógico em direção a uma noção ontológica das modalidades. Neste sentido, é importante prestar atenção num detalhe da formulação com a qual Kant inicia a elucidação dos Postulados, que é uma sentença condicional. A respeito das noções modais ele diz:

Pois, se estas não devem ter uma significação simplesmente lógica e exprimir a forma do pensamento analiticamente, mas devem concernir a coisas e sua possibilidade, realidade ou necessidade, então é necessário que se voltem para a experiência possível e sua unidade sintética unicamente na qual são dados objetos do conhecimento (KANT, 1980, A 219/B 267). 
A pergunta consiste em saber no que reside este dever, ou seja, por que as modalidades não devem ter uma significação simplesmente lógica? Por que se deve ir além de uma noção de possibilidade como o pensável sem contradição em direção a um conceito de possível como sendo o concordante com as condições formais da experiência? A resposta situa-se no campo das razões que justificam o projeto de limitar criticamente as categorias ao uso empírico, de tal forma a impedir que uma ilusão transcendental fomente problemas transcendentais, como, por exemplo, aqueles em que as noções modais são empregadas apenas em significação lógica com o intuito de provar a existência de um ente necessário, ou mesmo para a admissão de objetos possíveis jamais dados em qualquer experiência (GUYER, 1998, pp. 304, 308). A extensão para além do significado meramente lógico das modalidades relaciona-se, portanto, com aquilo que obriga a limitação crítica do uso das categorias, o que, como se sabe bem, não diz respeito tão somente à exclusão das metafísicas especiais do âmbito do conhecimento, mas, sobretudo à garantia da ampliação prática da razão pura.

Assim como a doutrina transcendental das modalidades nos ensina porque o conceito lógico de possibilidade é vazio, pois não contém critérios de existência e de sua satisfação, também o seu significado crítico auxilia a compreender porque é preciso ampliar o campo das modalidades para além das categorias modais da subsistência. Kant chamou de penúria do entendimento (penuria intellectus) aquele procedimento em que se permanece apenas com uma visão penetrante das notas características nominais das noções modais, e raramente as reais, o que está na base da confusão entre fenômeno e coisa em si, gerando as sub-repções transcendentais e todos os problemas metafísicos fundamentais (KANT, 2005 p. 278). Não seria abusivo dizer que a radicalização em direção ao campo modal da existência humana visa expor a pobreza da compreensão, que, ao saber de si mesma como finita e possível desde uma negatividade constitutiva, não diferencia entre modos de ser e nivela todos eles ao modo de ser da subsistência. Assim sendo, a ampliação do campo modal, reconhecendo um domínio em que há um primado do possível sobre o efetivo e o necessário, promovendo a restrição no Princípio de Plenitude, relaciona-se com o reconhecimento de um tipo de ilusão necessária, talvez mais básica do que a ilusão transcendental diagnosticada na Crítica da Razão Pura.

De acordo com Heidegger, a Dialética Transcendental não possui apenas um sentido negativo, como demarcação entre ciência e metafísica e eliminação das metafísicas especiais do campo do cognitivamente significativo, mas também possui um sentido positivo (REIS, 2011). Dito simplificadamente, este significado consiste em pretender que é no aparecimento das ilusões necessá- 
rias, com os problemas que geram e as soluções críticas que fomentam, é por essa dinâmica que se tematizam e elucidam as condições da significação. Deste modo, é com o diagnóstico dos efeitos da penúria da compreensão que se pode chegar às próprias condições que formam os horizontes estruturantes do encontro significativo com entes e objetos. Portanto, se as noções de necessidade, efetividade e possibilidade não devem ter uma significação apenas como categorias modais da subsistência, mas é preciso radicalizar a problemática em direção a um domínio em que o possível tem a primazia e a plenitude está em suspensão, então isso se justifica como forma abstrata de permitir o reconhecimento de diferentes classes de ilusões necessárias, uma tópica da ilusão que é também uma fenomenologia das condições do sentido. Pode-se conjecturar, por fim, que a elucidação dos análogos aos Postulados do Pensamento Empírico em Geral, correspondentes a todos os modos de ser admissíveis, identificaria as exigências normativas cuja satisfação não seria em primeiro lugar uma demanda de natureza teórica. Também na hermenêutica fenomenológica a ampliação para além do significado lógico e a radicalização do tratamento ontológico das noções modais estariam relacionadas com uma correspondência incondicional ao que é próprio de entes finitos e históricos, possuindo, portanto, um significado crítico.

Recebido em: 03.01.2014 | Aprovado em: 21.01.2014

AGUIRRE, A. 1991. Zum Verhältnis von modaler und praktischer Möglichkeit. In: ORTH,E. W. Perspektiven und Probleme der Husserlschen Phänomenologie. Freiburg/ München: Alber, pp. 150-182.

BECKER, O. 1952. Untersuchungen überden Modalkalkül. Meisenheim am Glam: Westkultur Verlag Anton Hain.

CARMAN, T. 2013. The Question of Being. In: WRATHALL, M. The Cambridge Companion to Heidegger's Being and Time. New York: Cambridge University Press, pp. 84-99.

FIGAL, G. 2001. Forgetfulness of God: Concerning the Center of Heidegger's Contributions to Philosophy". In:SCOTT, C., VALLEGA-NEU, S., SCHOENBOHM, D. Companion to Heidegger's Contributions to Philosophy. Bloomington and
Indianapolis: Indiana University Press, pp. 198-228.

GUYER, P. 1998. The Postulates of empirical Thinking in General and the Refutation of Idealism. In: MOHR, G., WILLASCHEK, M. Kant - Kritik der reinen Vernunft (Klassiker Auslegen). Berlin: Akademie Verlag GmbH, pp. 298-324.

HEIDEGGER, M. 1976. Die Grundprobleme der Phänomenologie. Frankfurt am Main: Vittorio Klostermann. 1983. Die Grundbegriffe der Metaphysik. Welt - Endlichkeit - Einsamkeit. Frankfurt am Main: Vittorio Klostermann.

.1986. Sein und Zeit. $16^{\mathrm{a}}$ ed. Tübingen: Max Niemeyer. 
.1987. Die Frage nach dem Ding (3 ${ }^{\mathrm{a}}$ ed). Tübingen: Max Niemeyer. 1991. Kant und das Problem der Metaphysik. $5^{\mathrm{a}}$ ed. Frankfurt am Main: Vittorio Klostermann.

.1996a. Vom Wesen des Grundes. In: HEIDEGGER, M. Wegmarken. Frankfurt am Main: Vittorio Klostermann, pp. 123-175.

.1996b. Kants These über das Sein. In: HEIDEGGER, M. Wegmarken. Frankfurt am Main : Vittorio Klostermann, pp. 445-480.

.2013. Seminare: Kant - Leibniz - Schiller.

Frankfurt am Main: Vittorio Klostermann.

HINTIKKA, J. \& KANNISTO, H. 1981. Kant on "The Great Chain of Being' or the Eventual Realization of All Possibilities: a Comparative Study. In: KNNUTTILA, S. Reforging the Great Chain of Being. Dordrecht: Reidel Publishing Company, pp. 287-308.

KANT, I. 1980. Crítica da Razão Pura. [trad.] Valerio Rohden e Udo Baldur Moosburger. São Paulo: Abril Cultural.

2005. Forma e princípios do mundo sensivel e do mundo inteligivel. [trad.] Paulo Licht R. dos Santos. In: KANT, I. Escritos pré-críticos. São Paulo: Editora UNESP, pp. 219-282.

KNUUTTILA, S. 1981. Reforging the Great Chain of Being. Dordrecht: Reidel Publishing Company.

LOVEJOY,A. 1936. The Great Chain of Being. Cambridge \& London: Harvard University Press.

MCDANIEL, K. 2009. Ways of Being. In: CHALMERS, D. MANLEY, D., WASSERMAN, R. Metametaphysics. Oxford: Clarendon Press, pp. 290-319.

MOHANTY, J. N. 1999. Husserl on "Possibility”. In:
MOHANTY, J. N Logic, Truth, and the Modalities. Dordrecht: Kluwer Academic Publishers, pp. 152-166.

MOTTA, G. 2012. Die Postulate des empirischen Denkens überhaupt. Berlin: De Gruyter.

REIS, R. 2011. Heidegger e a Ilusão Transcendental. In: AINBINDER, B. Heidegger y Kant. Buenos Aires: Editorial Teseo, pp. 183 - 218.

VON WRIGHT, G. H. 1951. An Essay in Modal Logic. Amsterdam: North-Holland Publishing Company. 